\title{
STRESS DEGRADATION STUDIES OF DRONEDARONE IN PHARMACEUTICAL DOSAGE FORM BY A VALIDATED STABILITY-INDICATING LC METHOD
}

\author{
V. K. AHIRRAO I, C. S. PATIL ${ }^{1}$, S. R. BEMBALKAR', M. V. KATARIYA ${ }^{l}$, V. S. SONNEKAR ${ }^{l}$, \\ R. P. MARATHE ${ }^{2}$ R. B. NAWALE ${ }^{2}$ and R. P. PAWAR ${ }^{1 *}$ \\ ${ }^{1}$ Department of Chemistry, Deogiri College, Aurangabad- 431004 (MS), India \\ ${ }^{2}$ Government college of Pharmacy Aurangabad-431004 (MS), India
}

(Received: January 23, 012 - Accepted: May 17, 2012)

\begin{abstract}
A simple, rapid, and precise method is developed for the quantitative estimation of dronedarone hydrochloride in presence of its degradants which are formed due to stress conditions. A chromatographic separation of the dronedarone and its degradants were achieved with Zorbax XDB $\mathrm{C}_{8} 150 \mathrm{x} 4.6 \mathrm{~mm}, 3.5 \mu \mathrm{m}$ analytical column using aqueous solution of $0.05 \mathrm{M}$ ammonium acetate and acetonitrile $(40: 60 \mathrm{v} / \mathrm{v})$. The instrumental settings are flow rate of $1.0 \mathrm{~mL} / \mathrm{min}$, column temperature at $30^{\circ} \mathrm{C}$, and detector wavelength of $220 \mathrm{~nm}$ using a photodiode array detector. Observed theoretical plates and tailing factor for dronedarone were 6577 and 1.09 respectively. Dronedarone was exposed to thermal, photolytic, hydrolytic and oxidative stress conditions, and the stressed samples were analysed by the proposed method. Peak homogeneity data of dronedarone is obtained using photodiode array detector. The stressed sample chromatograms demonstrate the specificity of the method for the estimation dronedarone in presence of its degradants. The described method showed excellent linearity over a range of $10-300$ $\mu \mathrm{g} / \mathrm{mL}$ for dronedarone. The correlation coefficient is 0.999 . The relative standard deviation of peak area for six measurements is always found to be less than $2 \%$. The proposed method was found to be suitable and accurate for quantitative determination and stability study of dronedarone.
\end{abstract}

Keywords: Liquid chromatography, Method validation, Pharmaceutical preparation, Dronedarone hydrochloride and Stress degradation.

\section{INTRODUCTION}

Dronedarone) is chemically $N$-\{2-butyl-3-[4-(3-dibutylaminopropoxy) benzoyl]benzofuran-5-yl\} methanesulfonamide (Fig. 1) ${ }^{1}$. Dronedarone is an anti-arrhythmic agent belonging to the benzofurane class of anti-arrhythmic compounds including amiodarone mainly used for the indication of cardiac arrhythmias (irregular heartbeat). It is used for the treatment of atrial fibrillation and atrial flutter in patients whose hearts have either returned to normal rhythm ${ }^{2-7}$. Method of preparation of dronedarone is reported in US patent $7312345^{8}$.

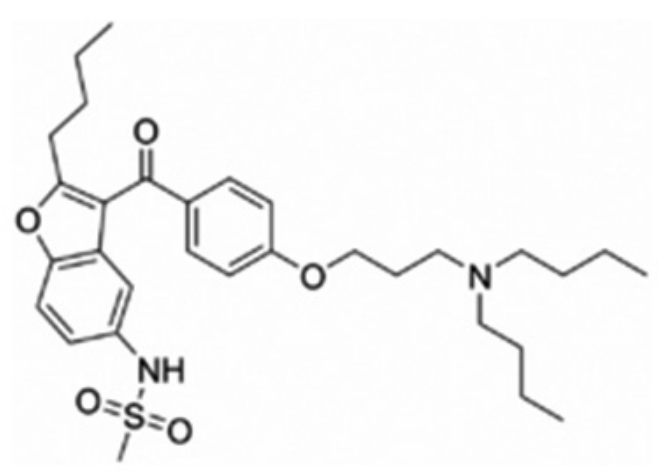

Fig.1. Chemical structure of Dronedarone Time (min).

Stress degradation testing is undertaken to demonstrate specificity when developing stability-indicating methods, particularly when little information is available about potential degradation products. The ICH guideline entitled "Stability Testing of New Drug Substances and Products" requires the stress testing to be carried out to elucidate the inherent stability characteristics of the active substances ${ }^{9-10}$. The purpose of stability testing is to provide evidence, how the quality of a drug substance or drug product varies with time under the influence of various environmental factors such as temperature, humidity, and light. It enables recommendation of storage conditions, retest periods, and shelf lives to be established. Regulatory agencies recommend the use of stabilityindicating methods for the analysis of stability samples. Thus, stress studies are required in order to generate the stressed samples, method development and method validation. Forced degradation of dronedarone was performed under stress conditions (acid, alkaline, photolytic, thermal and oxidative), to establish the stability indicating nature of the method, and stressed samples were analyzed by the proposed method. The proposed RP-HPLC method was validated by assessing its specificity, linearity, accuracy, precision, limits of detection and quantification, system suitability parameters, ruggedness and robustness.

Literature survey reveals that there are two HPLC-UV methods reported for analysis of dronedarone and its metabolite in serum and plasma ${ }^{11-12}$ and till date there is no stability indicating HPLC method reported for analysis of dronedarone hydrochloride in pharmaceutical dosage form. In the present study attempts were made to develop a rapid, economical, precise and accurate method for the estimation of dronedarone in presence of degradants.

\section{EXPERIMENTAL}

Chemicals and Reagents

Dronedarone hydrochloride standard was obtained from Sigma aldrich (India), ammonium acetate and acetonitrile (HPLC grade) were obtained from Merck Fine Chemicals (Mumbai, India). Sodium hydroxide $(\mathrm{NaOH})$, hydrochloric acid $(\mathrm{HCl})$ and hydrogen peroxide $\left(\mathrm{H}_{2} \mathrm{O}_{2}\right)$ were from Qualigens fine chemicals (Glaxo Ltd.) The 0.45 -Pump nylon filter was obtained from Advanced Micro devices Pvt. Ltd., (Ambala Cantt, India). The drug product of dronedarone label claim (Dronedarone tablet $400 \mathrm{mg}$ ) was purchased from the market. Double distilled water was used throughout the experiment. Other chemicals used were have analytical or HPLC grade.

Chromatographic conditions

A chromatographic system used was Agilent - 1100 series comprised of degasser, quaternary pump, auto injector, column compartment, photodiode array detector and the system was controlled through Chemstation software. Column used was Zorbax XDB $\mathrm{C}_{8}(150 \times 4.6 \mathrm{~mm}, 3.5 \mathrm{um}$, Agilent Technologies, USA) maintained at $30^{\circ} \mathrm{C}$ using column oven, eluted with mobile phase at the flow rate of $1.0 \mathrm{~mL} / \mathrm{min}$. The mobile phase consisted of aqueous solution of $0.05 \mathrm{M}$ ammonium acetate -acetonitrile $(40: 60 \mathrm{v} / \mathrm{v})$. The mobile phase filtered through $0.45 \mu \mathrm{m}$ nylon filter and degassed in ultrasonic bath prior to use. Measurements were made with injection volume $10 \mu \mathrm{L}$ and ultraviolet (UV) detection at $220 \mathrm{~nm}$. For analysis of forced degradation samples, the photodiode array detector was used in scan mode with a scan range of $200-400 \mathrm{~nm}$. The peak homogeneity was expressed in terms of peak purity and was taken directly from the spectral analysis report obtained using above-mentioned software.

\section{Standard solution}

Standard stock solution $(1.0 \mathrm{mg} / \mathrm{mL})$ was prepared by dissolving the drug in the diluent and standard solution was prepared by diluting them to the desired concentration. Diluent used for preparation was composed of water and 
acetonitrile in the ratio of 50:50 $(\mathrm{v} / \mathrm{v})$.

Preparation of tablet solution

20 tablets were taken and their average weight was calculated. The tablets were crushed to a fine powder, drug equivalent to $50 \mathrm{mg}$ of powder transferred to a $50 \mathrm{~mL}$ volumetric flask, and to this flask added $25 \mathrm{~mL}$ of diluent and the solution was sonicated for $10 \mathrm{~min}$. with intermittent shaking. Make up the volume with diluent and centrifuged at $10,000 \mathrm{rpm}$ for $10 \mathrm{~min}$. The centrifuged solution filtered through $0.45 \mu$ filter. From the filtered solution, $5 \mathrm{~mL}$ of solution was transferred into a $25 \mathrm{~mL}$ volumetric flask and diluted to volume with diluent.

Procedure for forced degradation study

Forced degradation of the drug product was carried out as per the ICH guideline ${ }^{10}$. The forced degradation study of the drug product was performed at thermolytic, photolytic, acid/base hydrolytic and oxidative stress conditions.

Acidic degradation

Weighed and transfer powder equivalent to $20 \mathrm{mg}$ of dronedarone in 10 $\mathrm{mL}$ volumetric flask. $3 \mathrm{~mL}$ of diluent and $3 \mathrm{~mL}$ of $1 \mathrm{~N} \mathrm{HCl}$ was added, keep the mixture at $60^{\circ} \mathrm{C}$ for three hours in water bath. Allow the solution to attend ambient temperature, neutralized with $1 \mathrm{~N} \mathrm{NaOH}$ solution to $\mathrm{pH} 7$ and the volume made up to with diluent. Further dilute this solution to achieve the concentration $200 \mu \mathrm{g} / \mathrm{mL}$ dronedarone.

Alkali degradation

Weighed and transfer powder equivalent to $20 \mathrm{mg}$ of dronedarone in 10 $\mathrm{mL}$ volumetric flask. $3 \mathrm{~mL}$ of diluent and $2 \mathrm{~mL}$ of $0.1 \mathrm{~N} \mathrm{NaOH}$ was added, keep the mixture at $60^{\circ} \mathrm{C}$ for half an hour in water bath. Allow the solution to attend ambient temperature, neutralized the solution with $0.1 \mathrm{~N} \mathrm{HCl}$ solution to $\mathrm{pH} 7$ and the volume made up to with diluent. Further dilute this solution to achieve the concentration $200 \mu \mathrm{g} / \mathrm{mL}$ of dronedarone.

Oxidative degradation

Weighed and transfer powder equivalent to $20 \mathrm{mg}$ of dronedarone in 10 $\mathrm{mL}$ volumetric flask. $3 \mathrm{~mL}$ of diluent and $2 \mathrm{~mL}$ of $30 \%$ hydrogen peroxide, keep the mixture at $60^{\circ} \mathrm{C}$ for one hour in water bath. Allow the solution to attend ambient temperature and the volume made up to with diluent. Further dilute this solution to achieve the concentration $200 \mu \mathrm{g} / \mathrm{mL}$ of dronedarone.

\section{Thermal degradation}

Weighed and transfer powder equivalent to $20 \mathrm{mg}$ of dronedarone kept in petri dish at $90^{\circ} \mathrm{C}$ for $24 \mathrm{hrs}$. Then the solution was prepared to achieve $200 \mu \mathrm{g} /$ $\mathrm{mL}$ of dronedarone.

\section{Photolytic degradation}

Weighed and transfer powder equivalent to $20 \mathrm{mg}$ of dronedarone in petri dish.Expose it to 1.2 million lux hours in 24 hours. Then the solution was prepared to achieve $200 \mu \mathrm{g} / \mathrm{mL}$ of dronedarone.

UV-Short $(254 \mathrm{~nm})$ degradation

About $100 \mathrm{mg}$ of drug product powder exposed to UV short light for 24 $\mathrm{hrs}$. The solution was prepared in diluent to achieve $200 \mu \mathrm{g} / \mathrm{mL}$ of dronedarone.

UV-Long $(366 \mathrm{~nm})$ degradation

About $100 \mathrm{mg}$ of drug product powder exposed to UV long light for $24 \mathrm{hrs}$. The solution was prepared in diluent to achieve $200 \mu \mathrm{g} / \mathrm{mL}$ of dronedarone.

\section{RESULTS AND DISCUSSION}

Optimization of the chromatographic conditions

To develop stability indicating method different stationary phases like $\mathrm{C} 18, \mathrm{CN}$ and different mobile phases containing buffers like phosphate, ammonium acetate and trifluoroacetic acid of different $\mathrm{pH}(3-5)$ and organic modifier (acetonitrile) were used.

Our objective of chromatographic method development was to separate all degradants peaks from analyte peak and tailing factor should be less than 2 .

The chromatographic separation of dronedarone from its degradants was achieved using Zorbax XDB C8 (15 x $4.6 \mathrm{~mm}$ x $3.5 \mu$ i.d.) column. Changing the composition of mobile phase optimization of chromatographic method is achieved. Zorbax XDB C8 column shows better performance as compared to other $\mathrm{C} 18$ or CN columns. System suitability data is shown in Table 1.

Table 1: System suitability.

\begin{tabular}{|l|l|}
\hline Parameters & Dronedarone HCl \\
\hline Retention time & $8.5 \mathrm{Min}$ \\
\hline USP Tailing & 1.09 \\
\hline Theoretical Plate Count & 6577 \\
\hline
\end{tabular}

Development studies confirmed that the aqueous solution of $0.05 \mathrm{M}$ ammonium acetate and acetonitrile was in the ratio of 40:60 $(v / v)$, the flow rate of mobile phase was $1.0 \mathrm{~mL} / \mathrm{min}$. and column temperature at $30^{\circ} \mathrm{C}$ are the optimal conditions. The analyte peak shape with less tailing, resolution from degradants and the chromatographic analysis time was less than $10 \mathrm{~min}$ In optimized conditions dronedarone and its degradants were well separated. Typical retention time of dronedarone peak was about $8.7 \mathrm{~min}$

Though conditions used for stress degradation were attenuated to achieve degradation in the range of $10-30 \% \%^{14-15}$. This is not achieved in case of photolytic degradation even after exposure for prolonged duration. The drug showed extensive degradation in acid hydrolysis, alkali hydrolysis, oxidative and in thermal condition. Table 2 indicates the extent of degradation, peak purity and assay of dronedarone under various stress conditions. Chromatographic peak purity data was obtained from the spectral analysis report and a peak purity value found to be greater than 990 , indicates a homogeneous peak. The peak purity values for analyte peak in the range of 999-1000 for tablet solution indicating homogeneous peaks and thus establishing the specificity of assay method. Fig. 2 (a-b) shows the chromatograms of dronedarone tablet solution and diluent. Fig. 3 (a-d) shows the chromatograms of acid hydrolysis degraded drug product, alkali hydrolysis degraded drug product, oxidative degraded drug product and thermal degraded drug product respectively. Fig. 4 (a-d) shows the peak purity spectra of dronedarone in acid hydrolysis degradation, alkali hydrolysis degradation, oxidative degradation and thermal degradation respectively.

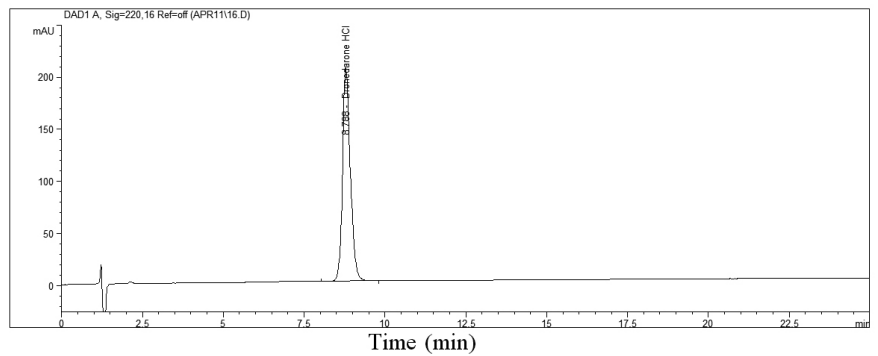

Fig. 2. (a) Chromatogram of tablet solution.

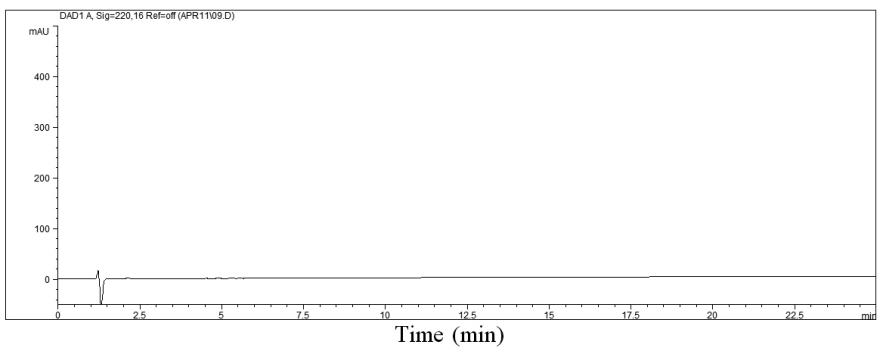

Fig. 2. (b) : Chromatogram diluent.

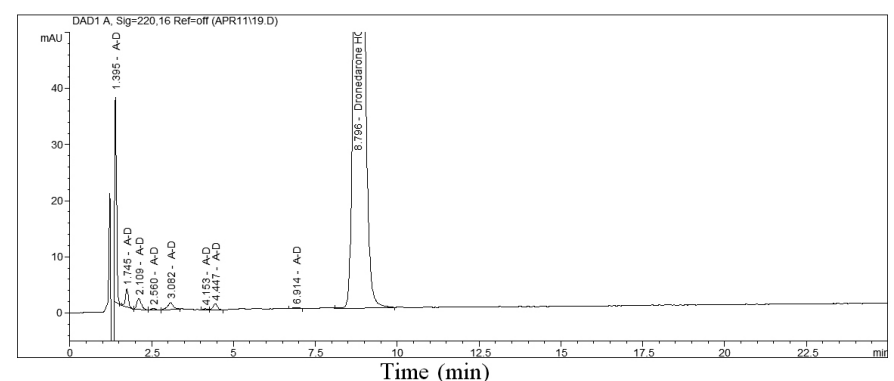

Fig. 3 (a) : Chromatogram of acid degradation. 


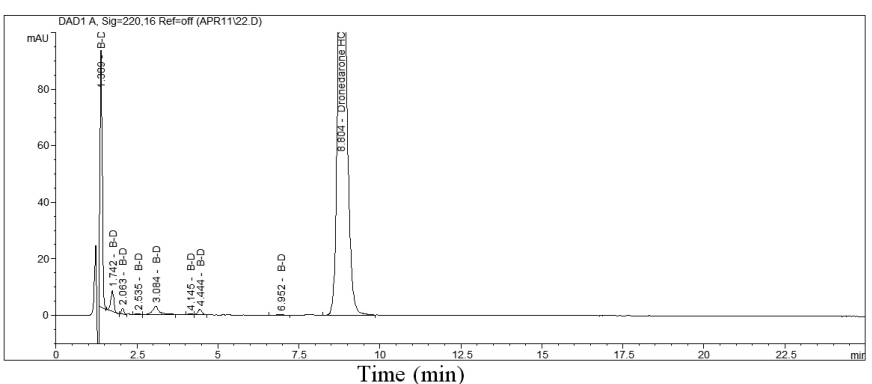

Fig. 3 (b) : Chromatogram of base degradation.

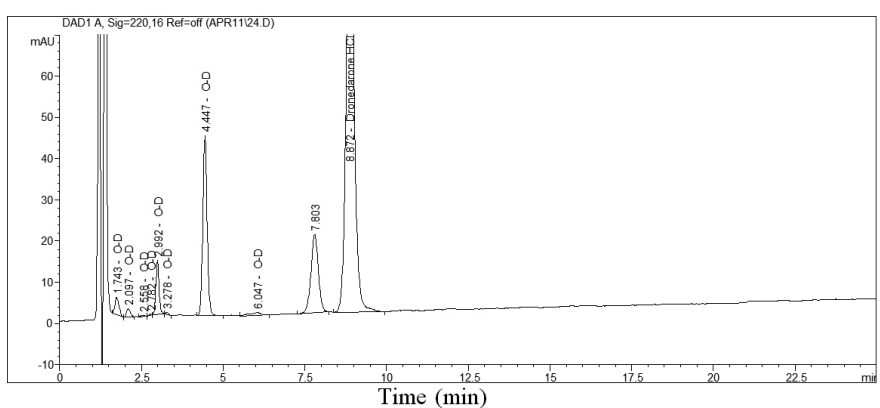

Fig. 3 (c) : Chromatogram of oxidative degradation.

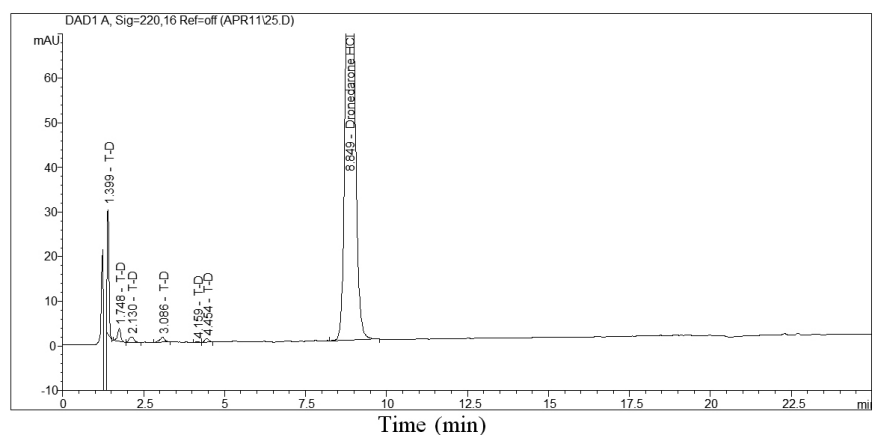

Fig. 3 (d): Chromatogram of thermal degradation.

Table 2: Results of forced degradation study

\begin{tabular}{|l|c|c|c|}
\hline Stress condition & $\begin{array}{c}\text { Degradation } \\
(\mathbf{\%})\end{array}$ & $\begin{array}{c}\text { Peak } \\
\text { Purity }^{\mathbf{a}}\end{array}$ & $\begin{array}{c}\text { Assay } \\
\mathbf{( \% )}\end{array}$ \\
\hline Acidic $\left(60^{\circ} \mathrm{C} / 3 \mathrm{hr}\right)$ & 12.33 & 999.905 & 88.18 \\
Alkali $\left(60^{\circ} \mathrm{C} / 30 \mathrm{Min}.\right)$ & 21.98 & 999.719 & 77.26 \\
Oxidative $\left(60^{\circ} \mathrm{C} / 1 \mathrm{hr}\right)$ & 26.18 & 999.902 & 73.53 \\
Thermal $\left(90^{\circ} \mathrm{C} / 24 \mathrm{hr}\right)$ & 8.52 & 999.369 & 92.12 \\
Photolytic & No degradation & 998.125 & 98.89 \\
UV-short $(24 \mathrm{hr})$ & No degradation & 999.631 & 99.52 \\
UV-long $(24 \mathrm{hr})$ & No degradation & 999.801 & 99.33 \\
\hline
\end{tabular}

${ }^{a}$ peak purity values in the range of 990-1000 indicate a homogeneous peak.

\section{Method validation}

\section{Specificity}

Photodiode array detection method was used as an evidence for the specificity of method and to evaluate the homogeneity of drug peak. The peak purity values are more than 999 for drug product at $220 \mathrm{~nm}$, which shows that the peaks of analyte were pure and also the formulation excipients and stress degradants were not interfering with the analyte peak.

Calibration and linearity:

Linearity experiment was tested from 10 to $150 \%$ of the targeted level of assay $(200 \mu \mathrm{g} / \mathrm{mL})$. Linearity solutions were injected in triplicate. The calibration graph was obtained by plotting peak area against the concentration of drug. The equation of calibration curve was found to be $y=12.967 \mathrm{x}+$ 1.3752. The calibration graph was found to be linear in the aforementioned concentrations with correlation coefficient 0.999 .
Table 3: Validation parameters.

\begin{tabular}{|l|l|}
\hline \multicolumn{1}{|c|}{ Parameters } & \multicolumn{1}{c|}{ Dronedarone HCl } \\
\hline Linearity range $(\mu \mathrm{g} / \mathrm{ml})$ & 10 to $300 \mu \mathrm{g} / \mathrm{mL}$ \\
\hline Regression equation & $\mathrm{y}=12.967 \mathrm{x}+1.3752$ \\
\hline $\mathrm{r} 2$ & 0.999 \\
\hline Method Precision $(\% \mathrm{RSD})$ & 0.23 \\
\hline Intermediate Precision $(\% \mathrm{RSD})$ & 0.39 \\
\hline LOD $(\mu \mathrm{g} / \mathrm{ml})$ & 0.126 \\
\hline LOQ $(\mu \mathrm{g} / \mathrm{ml})$ & 0.318 \\
\hline
\end{tabular}
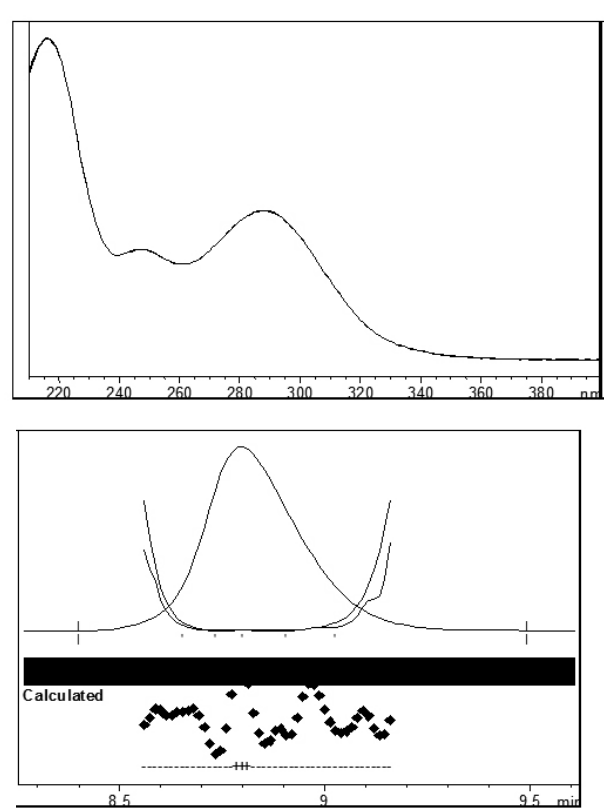

Fig. 4. (a) : Peak purity spectra of dronedarone in acid hydrolysis degradation.
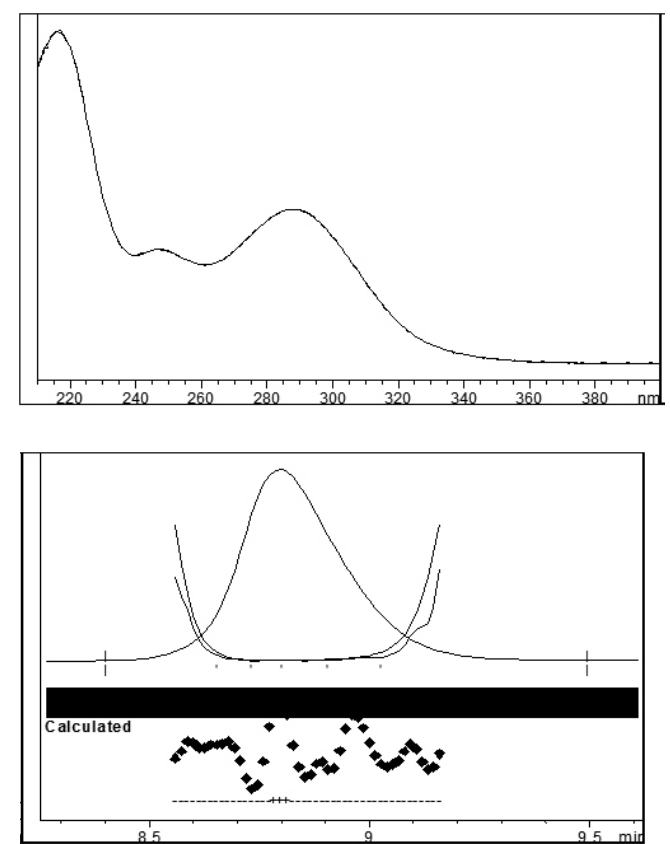

Fig. 4. (b) : Peak purity spectra of dronedarone in base hydrolysis degradation. 

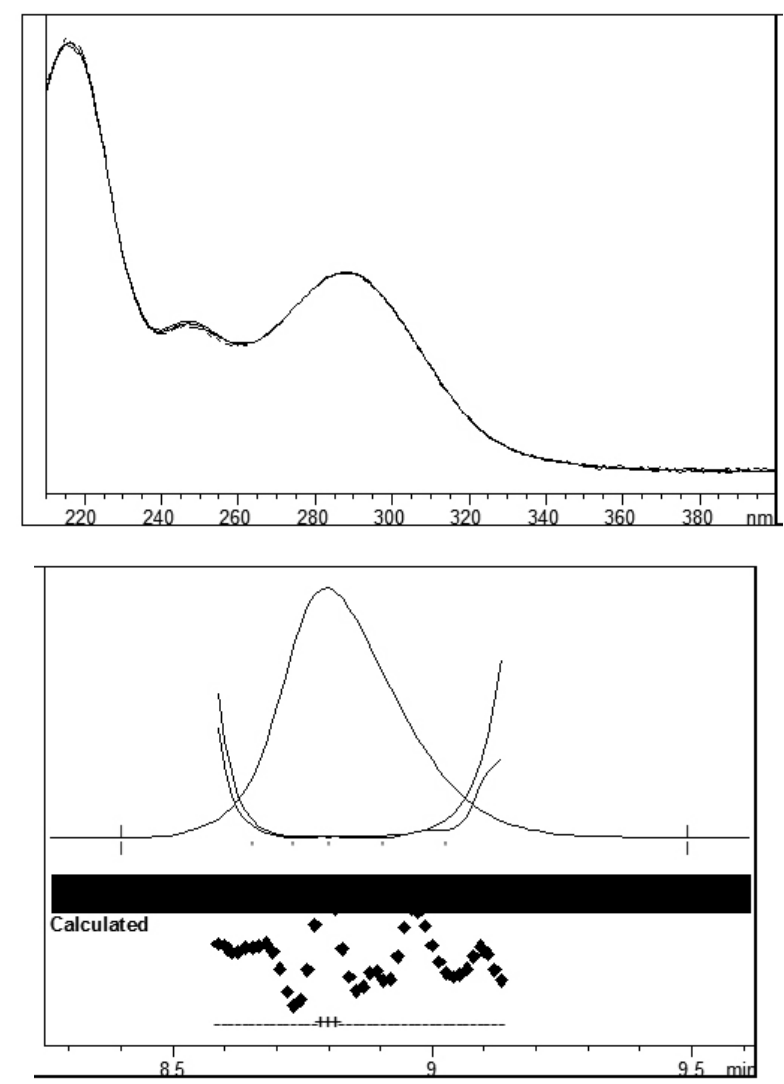

Fig. 4. (c) : Peak purity spectra of dronedarone in oxidative degradation.
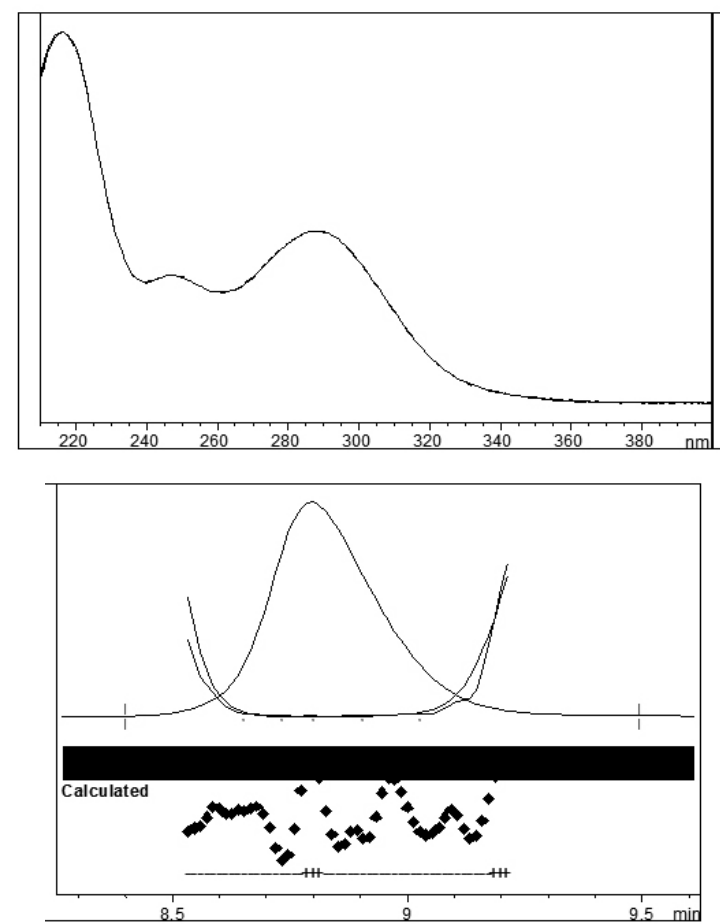

Fig. 4. (d) : Peak purity spectra of dronedarone in thermal degradation.

Precision (repeatability):

The precision of the method was studied by determining the concentration of drug in the tablets six times. The area \%RSD for dronedarone was 0.23 . Table 3 shows the results of the precision study and confirmed the method is reliable $(\mathrm{RSD} \%<2$ ).

Accuracy (recovery test)

Accuracy of the method was studied by recovery experiments. The recovery experiments were performed by adding known amounts of the drugs in the placebo. The recovery was performed at three levels, $80 \%, 100 \%$ and $120 \%$ of the label claim of tablet. The recovery samples were prepared as per the procedure mentioned in preparation of tablet solution. Three samples were prepared for each recovery level. The solutions were then analyzed, and the percentage recoveries were calculated. The recovery values for dronedarone for all nine determinations were in ranged of 99.09 to $100.16 \%$. The average recovery of three levels (nine determinations) was $99.33 \%(0.59)$. RSD values are shown in parenthesis. Recovery results are shown in Table 4 .

Table 4: Results of accuracy experiment.

\begin{tabular}{|c|c|c|c|}
\hline \multirow{2}{*}{ Level (\%) } & \multirow{2}{*}{$\begin{array}{c}\text { Amount of drug } \\
\text { spiked (mg) }\end{array}$} & Found & Recovery\% \\
\cline { 3 - 4 } & & (mg) & (n=3) \\
\hline 80 & 320.23 & 316.02 & 99.19 \\
\hline 100 & 400.53 & 398.29 & 99.53 \\
\hline & & & \\
\hline 120 & 480.45 & 479.11 & 99.88 \\
\hline
\end{tabular}

$\mathrm{n}=3$ determinations

Intermediate precision (reproducibility)

Intermediate precision of the method was determined by analyzing the samples six times on different days by different chemists using different analytical columns of the same make and different HPLC systems. The percentage assay was calculated. The assay results of chemist 1 and chemist 2 were $99.61 \%$ and $99.91 \%$ respectively. Results are shown in Table 3.

\section{Robustness}

Robustness of a method is the ability of method to remain unaffected by small changes in parameters. To determine robustness of the method, experimental conditions were purposely altered. Robustness was measured by evaluating assay, peak tailing, theoretical plates and resolution between main peak and oxidation degraded product at RRT 0.88 in all altered conditions..

The flow rate of the mobile phase was $1.0 \mathrm{~mL} / \mathrm{min}$. To study the effect of flow rate it was changed to 0.1 units from 1.0 to $0.9 \mathrm{~mL} / \mathrm{min}$ and $1.1 \mathrm{~mL} /$ min. The effect of column temperature was studied at $28^{\circ} \mathrm{C}$ and $32{ }^{\circ} \mathrm{C}$ instead of $30^{\circ} \mathrm{C}$, while other mobile phase components were kept constant. The effect of mobile phase composition was studied in aqueous solution of $0.05 \mathrm{M}$ ammonium acetate: acetonitrile $(38: 62 \mathrm{v} / \mathrm{v})$ and $(42: 58 \mathrm{v} / \mathrm{v})$. At all conditions, the sample was assayed in triplicate. The effect of detection wavelength was studied at $224 \mathrm{~nm}$ and $216 \mathrm{~nm}$. Assay \% of dronedarone at all deliberate conditions within the range of 98.21 to $99.60 \%$. Results are shown in Table 5 .

Table 5: Results of Robustness study.

\begin{tabular}{|c|c|c|c|c|}
\hline Sr. no. & Parameter & Variation & \multicolumn{2}{|c|}{$(n=3)$} \\
\hline \multirow[t]{2}{*}{1} & $\begin{array}{l}\text { Flow rate } \\
( \pm 10 \%)\end{array}$ & a) At $0.9 \mathrm{~mL} / \mathrm{min}$. & 99.22 & 2.9 \\
\hline & & b) At $1.1 \mathrm{~mL} / \mathrm{min}$. & 99.59 & 2.8 \\
\hline \multirow[t]{2}{*}{2} & $\begin{array}{l}\text { Organic } \\
\text { modifier }( \pm 2 \%)\end{array}$ & a) At $62 \mathrm{~mL}$ & 98.99 & 2.7 \\
\hline & & b) At $58 \mathrm{~mL}$ & 99.53 & 3.0 \\
\hline \multirow[t]{2}{*}{3} & $\begin{array}{l}\text { Temperature } \\
\left( \pm 2^{\circ} \mathrm{C}\right)\end{array}$ & a) At $28^{\circ} \mathrm{C}$ & 98.21 & 2.8 \\
\hline & & b) At $32^{\circ} \mathrm{C}$ & 99.33 & 2.8 \\
\hline \multirow[t]{2}{*}{4} & $\begin{array}{l}\text { Wavelength } \\
( \pm 4 \mathrm{~nm})\end{array}$ & a) At $216 \mathrm{~nm}$ & 99.51 & 2.9 \\
\hline & & b) At $224 \mathrm{~nm}$ & 99.60 & 2.9 \\
\hline
\end{tabular}

a Resolution between the oxidized degraded product at RRT 0.87 and dronedarone. 
Limit of quantification and Limit of detection (LOQ \& LOD)

The detection and quantification limits were evaluated from calibration curves plotted in concentration range of detection level to $300 \mu \mathrm{g} / \mathrm{mL}$. The formulae used were $\mathrm{LOD}=3.3 \sigma / \mathrm{S}$ and $\mathrm{LOQ}=10 \sigma / \mathrm{S}$ (where $\sigma=$ standard deviation of response and $\mathrm{S}=$ slope of calibration curve). LOD and LOQ for this method were found to be 0.126 and 0.318 respectively. These values indicated the method was very sensitive to quantify the drug.

The standard drug solutions for each value of LOD and LOQ concentration were injected 6 times. \% RSD values for the area of replicate injections were calculated.

\section{Solution stability}

The stability of the standard solution was tested at intervals of 12 and 24 hours. The stability of solutions was determined by comparing results of area $\%$ and peak purity of dronedarone. The area $\%$ values were within $0.5 \%$ after 24 hours. The results indicate that the solution was stable for 24 hours at ambient temperature as there was no formation of any unknown peak and solution remains stable. The \%RSD of peak area, and peak purity were 0.39 , 999.906 respectively.

\section{CONCLUSION}

The isocratic stability indicating LC method was developed for study of stress degradation of dronedarone in pharmaceutical preparations. The method is precised, accurate and requires short run time. The method was fully validated showing satisfactory data for all the method validation parameters tested. The developed method is a stability indicating and can be conveniently used by quality control department to determine the assay of pharmaceutical preparations and also to study the stability of dronedarone pharmaceutical dosage form.

\section{ACKNOWLEDGMENTS}

The authors are grateful to the Head-Department of chemistry, Deogiri College of Science Aurangabad, India for providing laboratory facility for this research work.

\section{REFERENCES}

1. http://en.wikipedia.org/wiki/Dronedarone.

2. A. Upaganlawar, H. Gandhi, and R. Balaraman, J Young Pharm., 2, 430, (2010).

3. K.M. Dale, C.M. White, Ann Pharmacother, 41, 599, (2007)

4. B.N. Singh, S.J. Connolly, H.J. Crijns, D. Roy, P.R. Kowey, A. Capucci, et al N Engl J Med., 357, 987, (2007).

5. P.J. Zimetbaum, N Engl J Med., 360, 1811, (2009).

6. S.H. Hohnloser, H.J. Crijns, van Eickels Met al., N Engl J Med, 360, 668, (2009).

7. L Køber, C. Torp-Pedersen, JJ McMurra et al., N Engl J Med, 358, 2678, (2008).

8. US Patent 7312345 - Process for the preparation of dronedarone.

9. International Conference on Harmonization, ICH Q1 A (R2), Stability Testing of New Drug Substances and Products, 2003.

10 International Conference on Harmonization, Q1B, "Photo stability testing of New drug substances and products, step 4", 1996.

11 R. W. Bolderman, J.J. Rob Hermans and J. G. Maessen, Journal of Chromatography B, 877, 1727 (2009).

12. Shilei Yang, Dafang Zhong, Xiaojian Dai, Xiaoyan Chen, Journal of Chromatography B, 879, 3071 (2011).

13. International Conference on Harmonization, ICH Q2B, Validation of Analytical Procedures, Methodology, 1996.

14. M. Bakshi M and S. Singh, J. Pharm. Biomed Anal., 28, 1011 (2002).

15. S. Baertschi. Pharmaceutical Stress Testing, Predicting Drug Degradation, Taylor \& Francis Group, Boca Raton, 2005, pp. 141-150. 